\title{
Do root-regolith-rock interactions govern critical zone-climate feedbacks over decades to centuries?
}

PAMELA L SULLIVAN ${ }^{1}$, SHARON BILLINGS ${ }^{2}$, LILI $^{3}$, JESSE NIPPERT ${ }^{4}$, HANG WEN $^{3}$, XI ZHANG ${ }^{1}$, VICTORIA MORENO $^{1}$, KAYALVIZHI SADAYAPPAN ${ }^{3}$, RACHEL $\mathrm{KEEN}^{4}$, DANIEL HIRMAS ${ }^{5}$, ALEJANDRO FLORES ${ }^{6}$, KATIE MURENBEELD $^{6}$, HOLLY BARNARD ${ }^{7}$, KAMINI SINGHA $^{8}$ AND HOORI AJAMI ${ }^{5}$

${ }^{1}$ Oregon State University

${ }^{2}$ University of Kansas

${ }^{3}$ Penn State University

${ }^{4}$ Kansas State University

${ }^{5}$ University of California - Riverside

${ }^{6}$ Boise State University

${ }^{7}$ University of Colorado - Boulder

${ }^{8}$ Colorado School of Mines

Presenting Author: Pamela.sullivan@oregonstate.edu

Drawing on multiple vignettes that range from grassland to montane ecosystems, we demonstrate the powerful ways in which root-regolith-rock interactions may modulate critical zoneclimate feedbacks. Our research integrates measurements of plant source water, root anatomy, water-stable soil aggregate size distributions, soil pore geometry (using multistripe triangulation and computerized tomography scans) and pore distributions (water retention measurements), subsurface water and gas fluxes (CO2 and $\mathrm{O} 2$ ), geophysical surveys, and geochemical analysis (regolith and water) to characterize subsurface properties and estimate hydrologic fluxes and states. In mesic tallgrass prairies, we find that the encroachment of woody vegetation plays an important role in altering critical-zone functions, specifically the hydrogeochemical behavior of grassland systems. Numerical modeling indicates that such changes over hundreds of years have strong ramifications on the depth to reaction fronts and generation of porosity. In a mesic hardwood forest, similar datasets show us that changes in land cover to agriculture or pine plantations strongly limits the depth to which critical-zone processes propagate downward from the surface and control biogeochemically active solute transport and transformations. In montane systems of western North America, heterogeneity in bedrock characteristics and subsurface topography influence where roots can mine resources. These properties govern the ability of forest stands to adapt to variable climatic conditions, and ultimately controls transport of solutes and nutrients to the river corridor. In each of these instances, water and carbon fluxes, their partitioning, and residence times shift with changing conditions, constraining land-atmosphere interactions and associated cloud formation and dynamics. We look to illuminate how such phenomena are key to quantifying critical zone-climate feedbacks on timescales of immediate concern to humans. 